\title{
A Simple Model of Mapping of Land Surface Temperature from Satellite Digital Images in Bangladesh
}

\author{
Shaikh Habiba Sultana ${ }^{1}$, M. Shahjahan Ali $^{2}$, Mst. Ashrafunahar Hena ${ }^{3}$ \\ 1,2,3 Applied Physics, Electronics and Communication Engineering, Islamic University, Bangladesh \\ ${ }^{1}$ habiba_kst@yahoo.com, ${ }^{2}$ jahanshah.iu@gmail.com, ${ }^{3}$ hena@aece.iu.ac.bd \\ M. Muntasir Rahman ${ }^{4}$ \\ ${ }^{4}$ Computer Science \& Engineering, Is lamic University, Bangladesh \\ ${ }^{4}$ muntasir@cse.iu.ac.bd
}

\begin{abstract}
Land Surface Temperature is a key parameter in energy budget models, estimating soil moisture, forest detection and forecasting, monitoring the state of the crops and many other applications. In this work, a method has been developed to retrieve land surface temperature using the National Oceanic and Atmospheric Administration (NOAA) of USA, Advanced Very High Resolution Radio meter (A VHRR) satellite images. The land surface temperature has been determined taking A VHRR images from February to December in a year. Seasonal variations have also been studied. The results have been presented in the false color composition (fcc) map for each month. Studying the resulting maps it is found that there is a marked spatial and seasonal variations in the surface temperature among different regions of the country. We could not compare our result with the measured data as, till now, no measured data of surface temperature is available for our country. But it is observed that our result is well in conformity with the observed air temperature of the country. This method can thus be used for long term monitoring of surface parameters for the country. The long term study of surface te mperature can be very much important for sustainable land resources development and to understand the effect of possible environmental changes.
\end{abstract}

Index Terms - Surface Temperature, Image Processing, NOAA-A VHRR, Satellite Image

\section{Introduction}

Rapid development of the space information technology forwarded the mankind day-by-day into a new horizon by providing satellite communication, navigation and specially by re mote sensing of the earth from space. Remote sensing is a science that becomes very putative nowadays. This science is not a new one but evolved as early as the mid 1950's and remote sensing from satellite has been used for earth observation more than three decades. But like other developing countries Bangladesh also deprived to uses and enforces the benediction of this science [1], [2].

The goal of the work is to show the entrance and overview methodology of the satellite monitoring of the land surface temperature.

Land Surface Temperature (LST) is an important factor in global change studies, estimating radiation budgets, heat balance studies, and forest detection and forecasting, monitoring the state of the crops, as a control for climate models and understanding the possible environmental changes [3].

Land Surface Temperature can be determined by measuring the radiation emitted by the earth's surface. This radiation will be converted into temperature brightness using the inverse of Planck's radiation equation. Unfortunately, land surface does not behave as a blackbody. The radiations measured by the satellite radiometer include also radiation emitted by the atmosphere and radiation reflected by the land surface. Gases and suspended particles in the atmosphere may absorb radiation emitted from objects, resulting in a decrease in the energy reaching a thermal sensor. Atmospheric absorption and scattering tend to make the signals from ground objects appear colder than they are. For this reason, measurement are usually made in two atmospheric absorption free regions (windows) of the electromagnetic spectrum ly ing between $3.5 \mathrm{~mm}$ to 3.9 $\mathrm{mm}$ and $10 \mathrm{~mm}$ to $13 \mathrm{~mm}$. Unfortunately, in this spectrum regions, there is residual gaseous absorption, mainly by water vapors, reported that the difference between the real Land Surface Temperature and the satellite surface temperature is of $7^{\circ} \mathrm{C}$ for a tropical atmosphere. By using a second infrared measurement, either at a different wavelength or at different zenith angle, it is possible to improve the estimation of the surface radiant temperature [4], [5], [6], [7]. 
In this work, the study area is the geographical area of Bangladesh which is located between $20^{\circ} 34^{\prime}$ to $26^{\circ} 38^{\prime}$ north latitude and $88^{\circ} 01^{\prime}$ to $92^{\circ} 42^{\prime}$ east longitude. The country has an almost uniformly humid, warm, tropical climate throughout the whole year. Because of its seasonal variation, prominent geographical features can be observed throughout the surface of the country.

The remainder of this paper is organized as follows: Section II gives the methodology to determine the land surface temperature. Section III presents the results and discussion. Conclusion and future work are given in the final section.

\section{Methodology}

Remote sensing data has been used for this study and the source of the data is near polar sun-synchronous satellite of NOAA K-L-M-N series. In this study particularly NOAA-16(L) and NOAA-17(M) imagery has been used.

The whole work has been carried out in two phases:

Phase one: Pre-processing of data.

Phase two: Determination of Land Surface temperature.

The flow chart of detailed methodology is shown in Fig. 1.

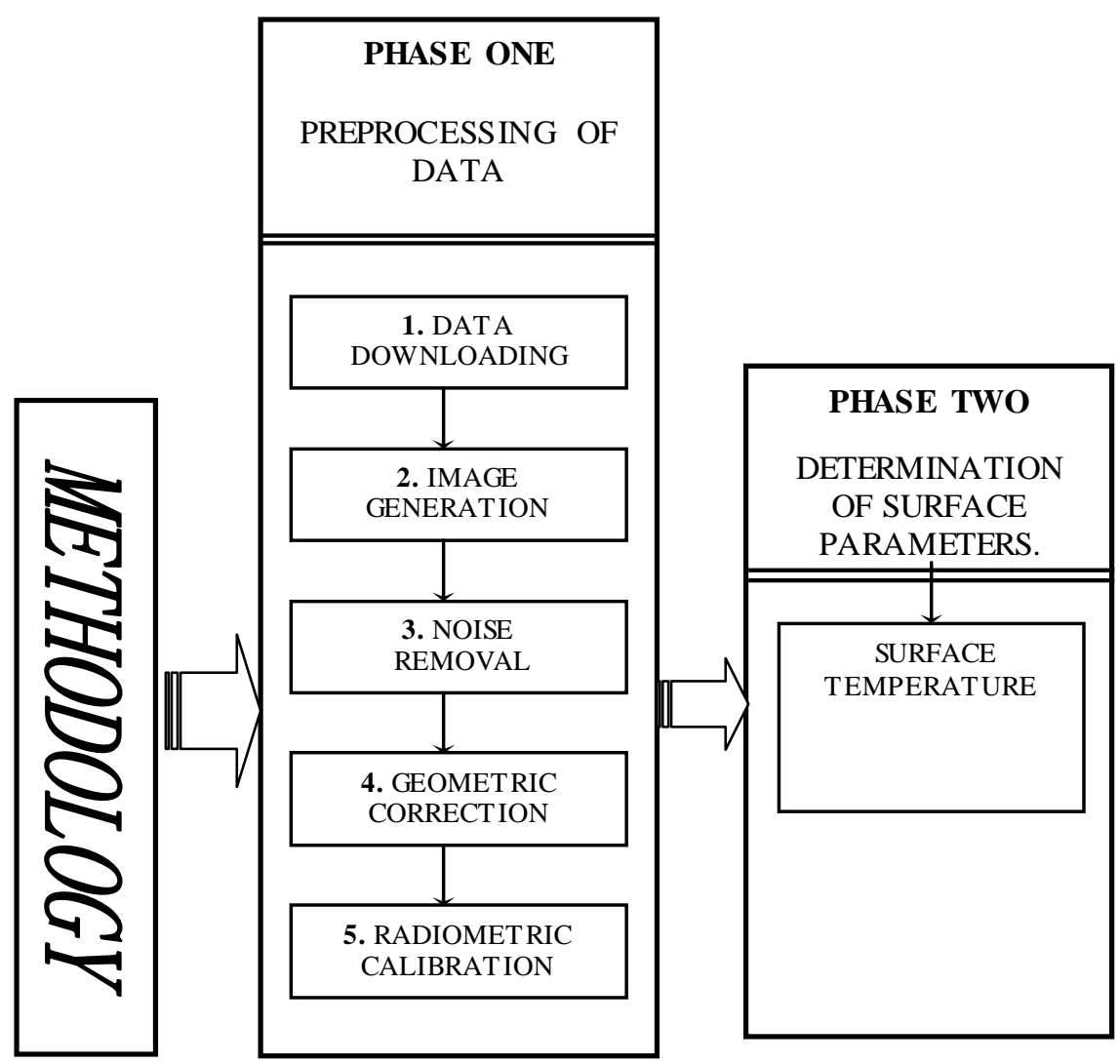

Fig. 1: Flow Chart of whole methodology

\subsection{Determination of Surface Parameters}

The surface reflectance and surface temperature are two very important agro meteorological parameters among many other parameters. After radiometric calibration of NOAA A VHRR/3, the visible channels (Channel 1 and 2) usually represent the reflectance and thermal channels (Channel 4 and 5) represent the temperature. The reflected and emitted radiances are affected by sun-target-sensor geometry and atmospheric and ground surface bidirectional effects. On the other hand as the thermal channels of NOAA AVHRR radiometers are not sensitive to solar elevation angle, only atmospheric correction is sufficient for finding surface temperature.[8], [9], [10], [11].

\subsection{Determination of Surface Temperature}

The reflected and emitted radiances are affected by sun-target-sensor geometry due to both atmospheric and ground surface bidirectional effects. The modulation of the data by atmospheric scattering and absorption by atmospheric particles, aerosols, ozone and water vapor should be taken into consideration. Many schemes have been developed to correct atmospheric intervention (Gao et. al. 1988, Paltridge and Mitchell 1990 ) [12]. To apply those methods, measured data for aerosol optical thickness, ozone absorption and water vapor are required. Usually these data are monitored and collected from climatological stations well distributed over the study area. Unfortunately, such facilities are scarce in 
Bangladesh and no reliable data on atmospheric parameters are readily available. To overcome this problem, we have applied in this research an alternative compositing approach to reduce the effect of atmospheric intervention. In this approach, the images have been processed monthly. All the day-time images for the given month were taken. Pixel values for channel-4 of one image were compared to the corresponding pixels of other images for that month. The maximu $m$ values for each pixel thus obtained were retained. The resultant image was the monthly composite image. As the monthly composite map contains data from different days and different weather and sun-target-sensor geometry, taking the maximum values for each pixel from the complex condition may remove the effect of spurious spatial and atmospheric variability. This process is accomplished by modeler of Erdas Imagine. After radiometric calibration, the thermal channel data represents surface temperature [13], [14], [15], [16].

\section{Results \& Discussions}

Bangladesh has a tropical monsoon-type climate, with six seasons. After evaluate the land surface temperature of regions of Bangladesh which are estimated in seasonal periods of Bangladesh, the results are given below-

Table 1: Land Surface Temperature

\begin{tabular}{|c|c|c|}
\hline Seasons & $\begin{array}{c}\text { Maximum } \\
\text { Temperature }\end{array}$ & $\begin{array}{c}\text { Minimum } \\
\text { Temperature }\end{array}$ \\
\hline Summer & $31-35^{\circ} \mathrm{C}$ & $21-23^{\circ} \mathrm{C}$ \\
\hline Rainy season & $27-30^{\circ} \mathrm{C}$ & $11-15^{\circ} \mathrm{C}$ \\
\hline Autumn & $24-26^{\circ} \mathrm{C}$ & $16-20^{\circ} \mathrm{C}$ \\
\hline Late Autumn & $24-30^{\circ} \mathrm{C}$ & $11-20^{\circ} \mathrm{C}$ \\
\hline Winter & $21-23^{\circ} \mathrm{C}$ & $11-15^{\circ} \mathrm{C}$ \\
\hline Spring & $27-30^{\circ} \mathrm{C}$ & $16-20^{\circ} \mathrm{C}$ \\
\hline
\end{tabular}

The developed method has been used to obtain the surface temperature over Bangladesh. Table 1 shows the variation of land surface temperature for six seasonalperiods of Bangladesh.

These results are well in conformity with the observed air temperature values for the seasons. The variation of surface temperature with seasonal changes can be understood by the knowledge of incoming solar radiation and rainfall of the country.

\subsection{Summer (March to May)}

Fig. 2, Fig. 3, and Fig. 4 show the false color composition (FCC) maps of surface temperature for the month of March, April and May in summer.

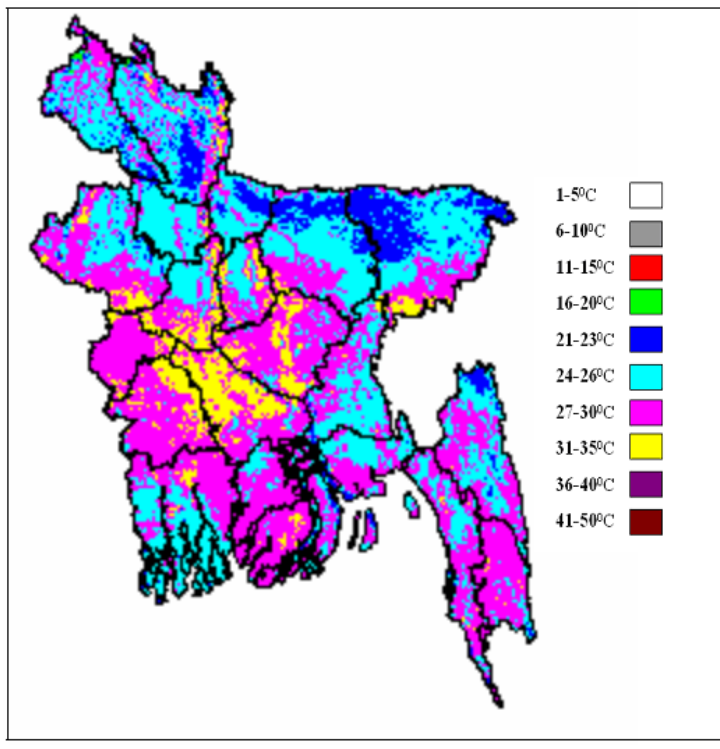

Fig. 2: Land Surface Temperature in March.

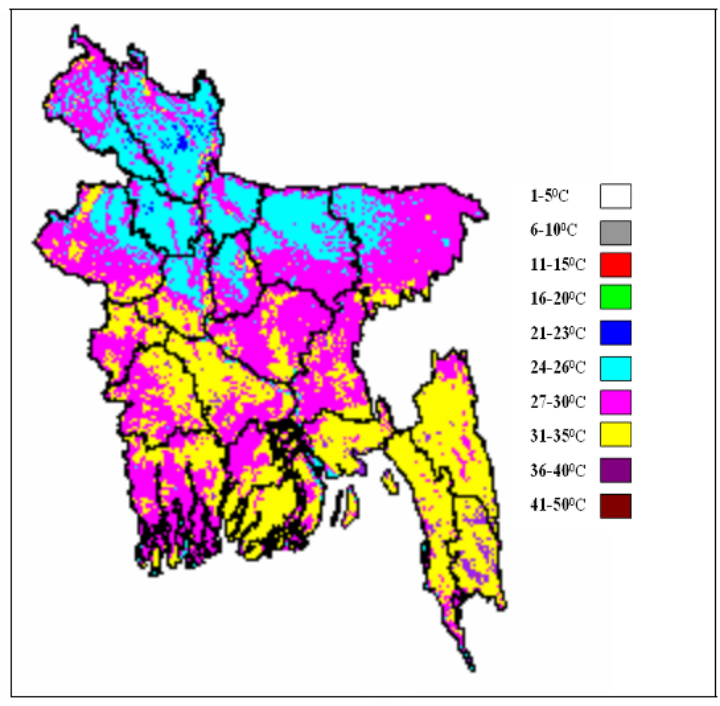

Fig. 3: Land Surface Temperature in April

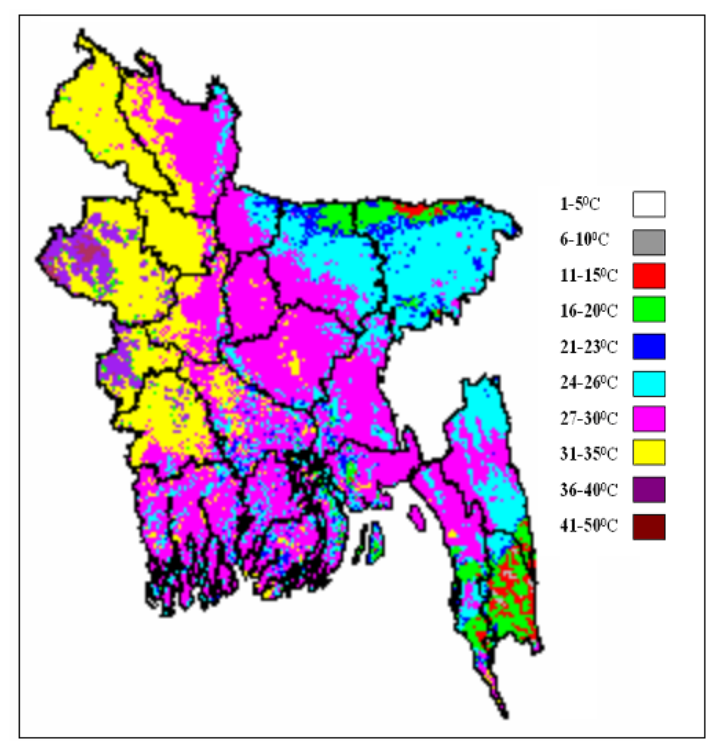

Fig. 4: Land Surface Temperature in May 
For the month of March land surface temperature in the middle parts and southern regions are seen to vary from $27^{0} \mathrm{C}$ to $30^{\circ} \mathrm{C}$. Land surface temperature in northern and south-eastern areas of the country is 24$26^{\circ} \mathrm{C}$. Whereas the highest value has been observed in some of the middle parts where temperature is $31-35^{\circ} \mathrm{C}$ and the lowest value in the northern regions where temperature is $21-23^{0} \mathrm{C}$.

Land surface temperature in April is $24-26^{\circ} \mathrm{C}$ in the northern regions. Land surface temperature in the eastern and western areas of the country is $26-30^{\circ} \mathrm{C}$ whereas the highest value has been observed in some of the middle parts and south-eastern regions where temperature is $31-35^{\circ} \mathrm{C}$.

For the month of May land surface temperature in the western regions are seen to vary from $31^{\circ} \mathrm{C}$ to $35^{\circ} \mathrm{C}$. Temperature in some eastern and hilly areas of the country is $24-26^{\circ} \mathrm{C}$. Whereas the highest value has been observed in some of the western parts where temperature is $36-40^{\circ} \mathrm{C}$ and the lowest value in some of the northern and southern regions where temperature is $11-15^{0} \mathrm{C}$.

It is seen that in summer, there is a wide variation of temperature throughout the country because in summer, land reaches to a higher temperature than the ocean. The hot air over the land tends to rise, creating an area of low pressure. This creates an extremely constant wind blowing toward the land.

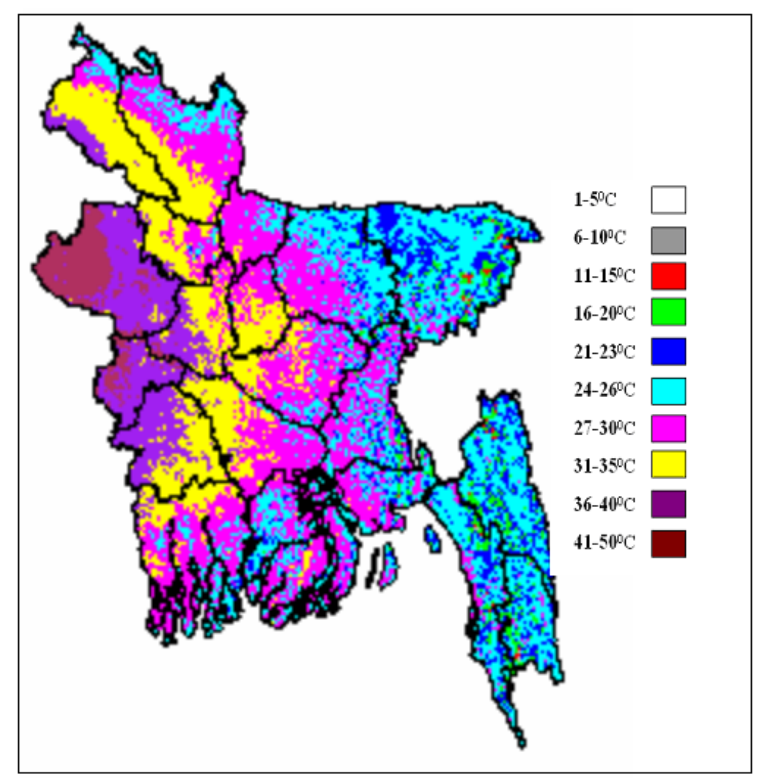

Fig. 5: Land Surface Temperature in June

\subsection{Rainy Season (June to August)}

Fig. 5 and Fig. 6 show the false color composition (FCC) maps of surface temperature for the month of June and July of in rainy season. Temperature map for the month of August could not be prepared because for this month all the images were cloud contaminated. For the month of June land surface temperature in the eastern regions are seen to vary from $24^{0} \mathrm{C}$ to $26^{\circ} \mathrm{C}$. It is $27-30^{\circ} \mathrm{C}$ in northern areas, in some of the middle parts of the country and in the coastal areas. Whereas the highest value has been observed in some of the western parts where temperature is $41-50^{\circ} \mathrm{C}$ and the lowest value in some of the eastern regions, where te mperature is $16-23^{\circ} \mathrm{C}$. Land surface temperature is $31-40^{\circ} \mathrm{C}$ in western areas.

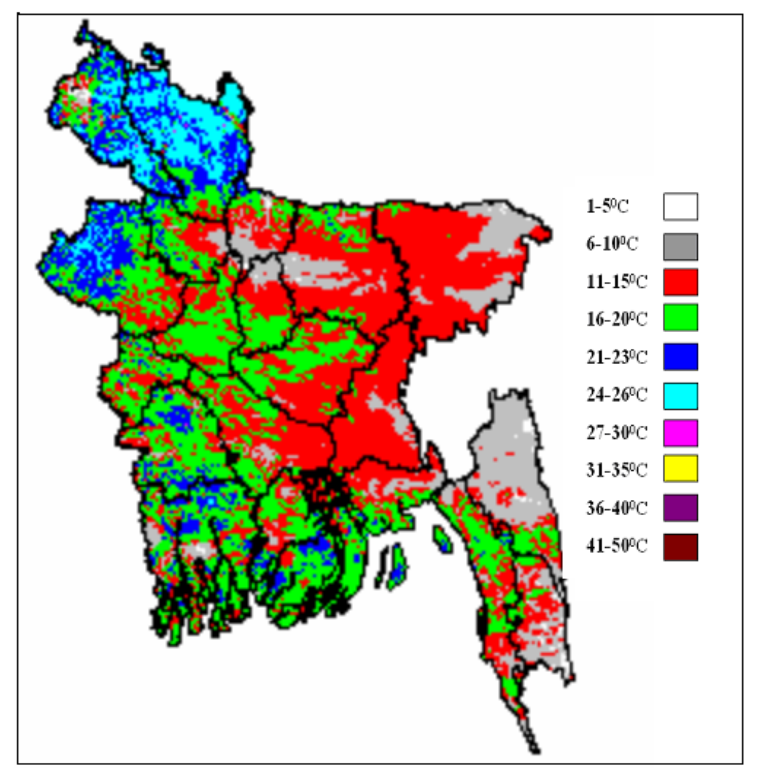

Fig. 6: Land Surface Temperature in July

Land surface temperature in July is $11-20^{\circ} \mathrm{C}$ in the most of the middle parts and southern regions of the country. In some southern and western areas of the country, it is $21-23^{\circ} \mathrm{C}$. The highest value has been observed in some of the north-western parts where temperature is $24-26^{\circ} \mathrm{C}$ and the lowest value in some eastern regions where temperature is $6-10^{\circ} \mathrm{C}$.

The observed lowest temperature (6-10 degree) in some eastern, and some small parts of other regions may be due to the presence of sub-pixel clouds in these regions. Sub-pixel clouds are very small scale clouds, detection of which is very difficult.

It is seen that in rainy season, there is a wide variation of temperature throughout the country. Because in Bangladesh, which has both the world's largest delta system and the greatest flow of river water to the sea, water rules the land properties. The rainy seas on coincides with the summer monsoon. Rainfall of this season accounts for 70 to 85 percent of the annual total. This is caused by the tropical depression that enters the country from the Bay of Bengal.

\subsection{Autumn (September to October)}

Fig. 7 and Fig. 8 show the false color composition (FCC) maps of surface temperature for the month of September and October in autumn. For the month of September land surface temperature in the northern, western and middle areas of the country are seen to vary 
from $24^{0} \mathrm{C}$ to $26^{\circ} \mathrm{C}$.It is $21-23^{0} \mathrm{C}$ in southern areas and in the coastal areas. Whereas the highest value has been observed in northern parts where temperature is 27 $30^{\circ} \mathrm{C}$ and the lowest value in some of the southern regions where temperature is $16-20^{\circ} \mathrm{C}$.

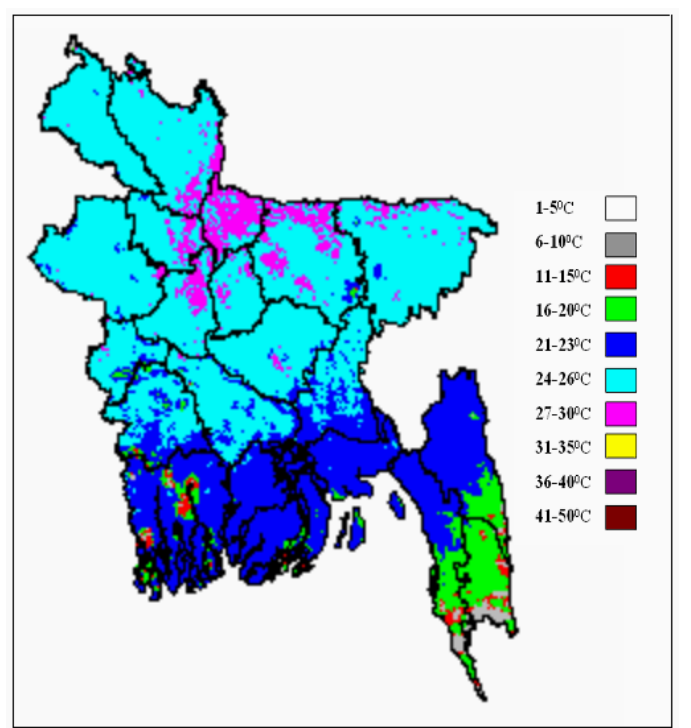

Fig. 7: Land Surface Temperature in September

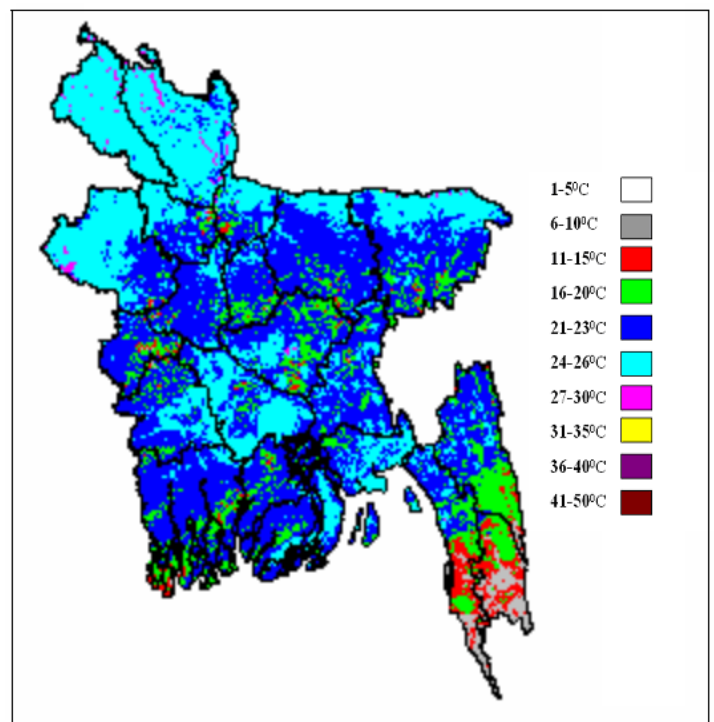

Fig. 8: Land Surface Temperature in October

For the month of October land surface temperature in most areas of the country are seen to vary from $21^{0} \mathrm{C}$ to $23^{\circ} \mathrm{C}$. It is $16-20^{\circ} \mathrm{C}$ in southern and the middle areas. Whereas the highest value has been observed in some north and southern parts where temperature is $24-26^{\circ} \mathrm{C}$ and the lowest value in some of the southern regions where temperature is $11-15^{\circ} \mathrm{C}$.

It is seen that in autumn, there is a wide variation of temperature throughout the country. Because as September begins, the skies are blue and a cool wind started to blow. Although the air is humid, there is a slight chill late at night.

\subsection{Late autumn (October to November)}

Fig. 8 and Fig. 9 show the false color composition (FCC) maps of surface temperature for the month of October and November in late autumn. For the month of November land surface temperature in most areas of the country are seen to vary from $24^{0} \mathrm{C}$ to $26^{\circ} \mathrm{C}$. Whereas the highest value has been observed in the east and southern regions where temperature is $27-30^{\circ} \mathrm{C}$ and the lowest value in some northern regions where temperature is $21-23^{0} \mathrm{C}$.

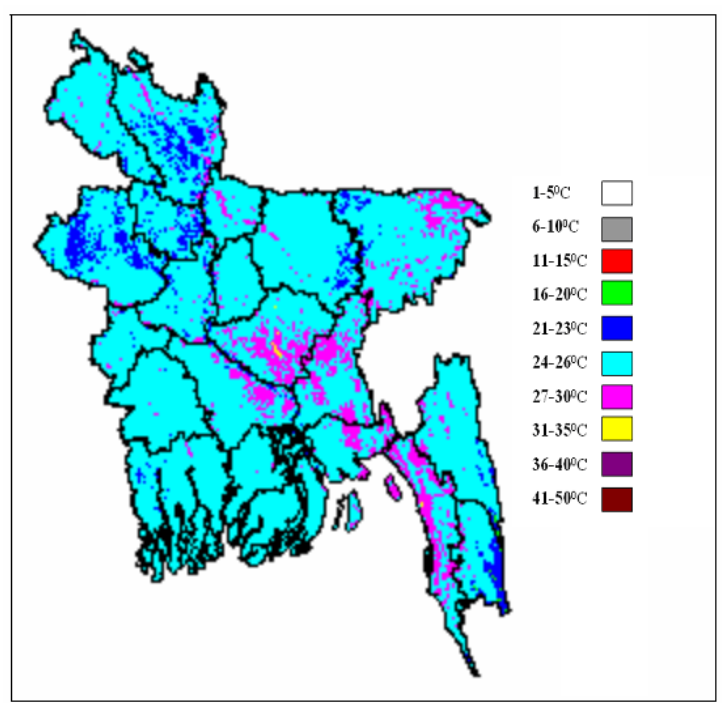

Fig. 9: Land Surface Temperature in November

\subsection{Winter (December to January)}

Fig. 10 shows the false color composition (FCC) maps of surface temperature for the month of December of (winter period). For the month of December land surface temperature in most areas of the country is seen to vary from $21^{\circ} \mathrm{C}$ to $23^{\circ} \mathrm{C}$. The temperature is $24-26^{\circ} \mathrm{C}$ in eastern, southern and middle areas. Whereas the lowest value has been observed in coastal and southeastern areas temperature is $16-20^{\circ} \mathrm{C}$.

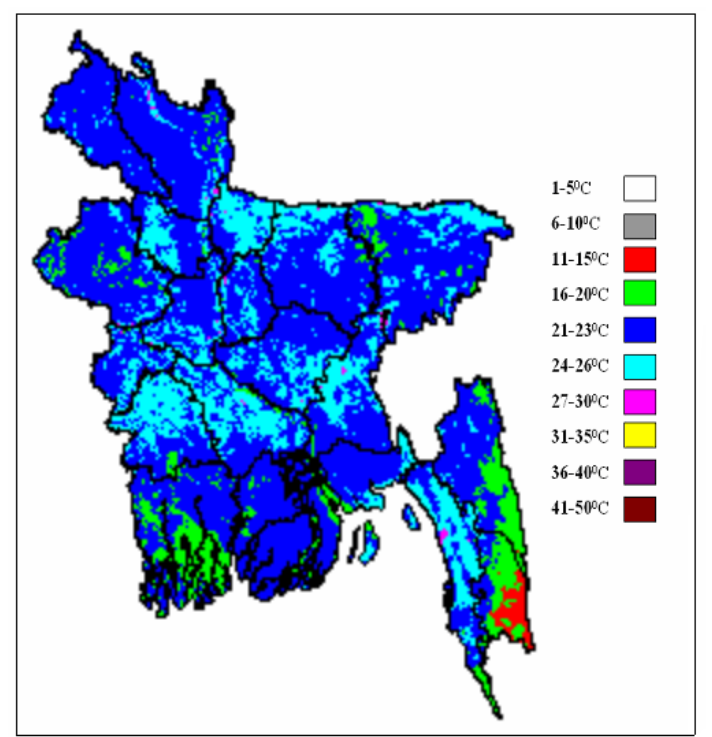

Fig. 10: Land Surface Temperature in December 
It is seen that in winter, there is a wide variation of temperature throughout the country. From midNovember to early January, the weather becomes more arid and less humid. The hot air over the ocean rises, creating a low pressure area and a breeze from land to ocean. Because the temperature difference between the ocean and land is less than in summer, the winter monsoon wind is not as constant. Characteristics of the cool and dry winter season are: low temperature, cool west or northwesterly winds, clear skies and low rainfall.

\subsection{Spring (February to march)}

Fig. 11 and Fig. 2 show the false color composition (FCC) maps of surface temperature for the month of February and March in spring. For the month of February land surface temperature in most areas of the country are seen to vary from $21^{0} \mathrm{C}$ to $23^{0} \mathrm{C}$. It is $16-$ $20^{\circ} \mathrm{C}$ in northern areas of the country. Land surface temperature is $24-26^{\circ} \mathrm{C}$ in southern and south-eastern areas. Whereas the highest value has been observed in southern areas temperature is $27-30^{\circ} \mathrm{C}$.

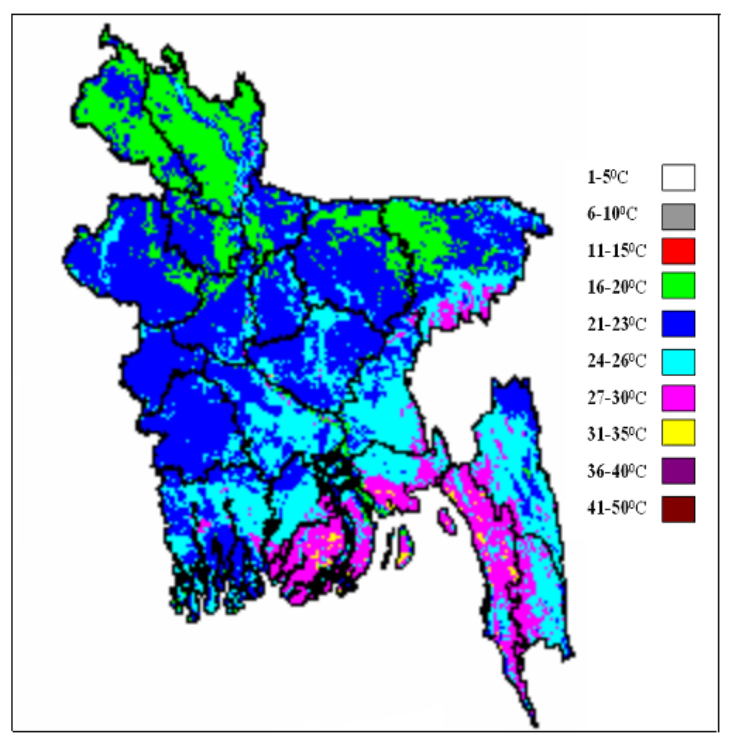

Fig. 11: Land Surface Temperature in February

\section{Conclusion}

In this paper, a method for estimation of land surface temperature from NOAA-A VHRR radiometer data has been developed. Using this method surface temperature maps for three main seasonal periods of Bangladesh have been constructed. Precise atmospheric correction scheme could not be utilized in the current study due to unavailability of measured meteorological parameters. Also, the absolute values of temperatures obtained in this study could not be verified against in-situ measurements as no ground measured data for the study area are currently available. As a result there may have some errors in the derived temperature values, but the pattern of the temperatures thus obtained are in good agreement with the environmental conditions of the study area. The study also yields the intra-seas on and seasonal variations of temperatures. The results obtained in this study correspond well with the local environmental conditions of the respective regions. It can be concluded from the study that this method can be utilized for long-term determination of land surface temperature for Bangladesh.

\section{References}

[1] M. A. Reddy; 1996; Text Book of Remote Sensing and Geographical Information Systems, 2nd Edition, B. S. Publications, Hyderabad, India.

[2] P.L.N. Raju; 2003; Fundamentals of Geographical Information System; Satellite Remote Sensing and GIS Applications in Agricultural Meteorology; India. URL: www.wamis.org.

[3] D. C. Agarwal; 2001; Satellite Communication; Khanna Publishers; India.

[4] URL: www.Gis lab.ghsph.edu/intr-ist.htm.

[5] URL: www.Land sat.meteo.pt/algorithms.jsp.

[6] URL: www.Eng.tethys.cat/q=node/50.

[7] URL: www.En.scientific commons.org.

[8] France, G.B. \& Cracknell, A.P., 1994. Retrieval of land and sea surface temperature using NOAA-11 AVHRR data in north-eastern Brazil, International Journal of Remote Sensing, 15, 1695-1712.

[9] Dousset, B. \& Gourmelon F., 2003. Satellite mu ltisensor data analysis of urban surface temperatures and landcover, ISPRS Journal of Photogrammetry and Remote Sensing. 58, (1-2), 43-54.

[10] S. Yang, Y. Q. Wang and P. V. August (Department of Natural Resources Science, University of Rhode Island,USA),2001. URL:www.iseis.org/jei/abstract.asp no $=200400035$.

[11] Bianba Ciren, Basang Zhuoga ,X. Deng ,S. Zhang. URL: $\quad$ www.cat.inist.fr/a modele $=$ afichen \& cpsidt=13778129.

[12] Gao, W., R.L. Coulter, B.M. Lesht, J. Qui and M.L. Wesely (1988) Estimation clear-sky regional surface fluxes in the southern Great Plains atmospheric radiation measurement site with ground measurement and satellite observations. J. Appl. Meteor., Vol-37, pp 5-22.

[13] Mc.Clain,Foroogh Beik and M.Reza. (Remote Sensing Division, Surveying and Geomatics Engineering Department, Faculty of Engineering, University of Tehran, Tehran, Iran).URL: www. GISdevelop ment.net ---> Technology ---> Remote Sensing.

[14] Fuat Ince, 1983. Dig ital image processing systems and remote sensing, Int. J. Remote Sensing, Vol.-4, N-1, pp. 129-148. 
[15] M. S. Ali, H. Rahman and R.K. Mazumder,(2007). Geo metric Correction of NOAA AVHRR Satellite Images for Solar Radiation Applications J. Bangladesh Electron Soc. Vol-7 ,No:1-2, PP: 8790 .

[16] Liu H, Weng Q (Center for Urban and Environmental Change, Department of Geography Geology and Anthropology, Indiana State University, Terre Haute, IN 47809, USA.). URL: www.ncbi.nlm.gov/pubmed/17899413.

\section{Authors' Profiles}

Shaikh Habiba Sultana: Student of the Department of Applied Physics, Electronics \& Communication Engineering, Islamic University, Bangladesh.

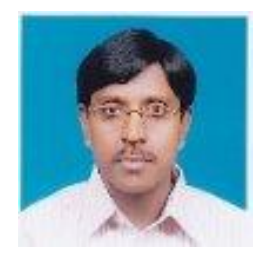

M. Shahjahan Ali: Associate Professor of the Department of Applied Physics, Electronics \& Communication Engineering, Islamic University, Bangladesh.

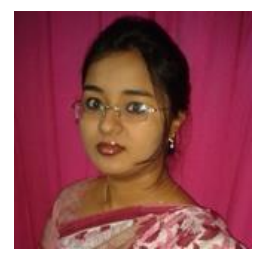

Mst. Ashrafunnahar Hena: Lecturer of the Department of Applied Physics, Electronics \& Communication Engineering, Islamic University, Bangladesh.

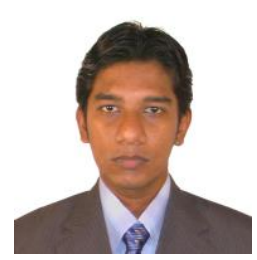

M. Muntasir Rahman: Lecturer of the Department of Computer Science \& Engineering, Islamic University, Bangladesh.

How to cite this paper: Shaikh Habiba Sultana, M. Shahjahan Ali, Mst. Ashrafunahar Hena, M. Muntasir Rahman,"A Simple Model of Mapping of Land Surface Temperature from Satellite Digital Images in Bangladesh", International Journal of Information Technology and Computer Science(IJITCS), vol.5, no.1, pp.51-57, 2013.DOI: 10.5815/ijitcs.2013.01.05 